\title{
Matrix Isolation Study of Methyl Propiolate in Argon and Nitrogen Matrices
}

\author{
S. Lopes, ${ }^{1 *}$ T. Nikitin ${ }^{2}$ and Rui Fausto ${ }^{1 *}$ \\ ${ }^{1}$ CQC, Department of Chemistry, University of Coimbra, 3004-535 Coimbra, Portugal \\ ${ }^{2}$ CFisUC, Department of Physics, University of Coimbra, 3004-516 Coimbra, Portugal
}

\begin{abstract}
Methyl propiolate $\left(\mathrm{HC} \equiv \mathrm{CCOOCH}_{3}\right.$, MP) isolated in argon and nitrogen matrices was experimentally studied by infrared spectroscopy and by quantum chemical calculations. The calculations, carried out at the DFT(B3LYP) and MP2 levels of theory, predict the existence of two planar conformers. In situ broadband UV light $(\lambda>200 \mathrm{~nm})$ irradiation of matrix-isolated MP, led to the production of new bands ascribed to conformer $\mathbf{I I}^{\prime}$, testifying the occurrence of the $\mathbf{I}^{\prime} \rightarrow$ II' photoisomerization. No other photochemical processes were observed. Assignment of the IR spectra of both conformers is presented, considerably extending the vibrational information available for this molecule hitherto.
\end{abstract}

\section{Keywords}

Methyl propiolate / Photoinduced conformational change / matrix isolation / IR spectra

${ }^{*}$ Corresponding authors e-mails:

Susy Lopes: susylopes@qui.uc.pt

Rui Fausto: rfausto@ci.uc.pt 


\section{INTRODUCTION}

Methyl propiolate $\left(\mathrm{HC} \equiv \mathrm{CCONH}_{2}, \mathrm{MP}\right)$ is the methyl ester of propiolic acid. From the structural

point of view, MP consists of an ester group attached to an acetylenic fragment $(\mathrm{H}-\mathrm{C} \equiv \mathrm{C}-)$. In the ground state, the methyl ester group adopts the cis orientation $\left(\mathrm{O}=\mathrm{C}-\mathrm{O}-\mathrm{CH}_{3}\right.$ dihedral angle equal to $0^{\circ}$ ), with one of the methyl hydrogen atoms occupying the anti-periplanar position in relation to the carbonyl group $\left(\mathrm{H}-\mathrm{C}-\mathrm{O}-\mathrm{C}(=\mathrm{O})\right.$ dihedral angle equal to $\left.180^{\circ}\right)$. This geometrical pattern corresponds to the usual conformational behavior for carboxylic esters.[1-7]

MP is used as starting material in many important chemical reactions. It has been used in the synthesis of different types of compounds via domino reactions,[8-10] as an intermediate in cycloadditions, $[11,12]$ as a starting material for the production of substituted triazoles with antimicrobial activity.[13] MP has also been widely used in reactions with vinyl gold complexes,[14] bis-insertion reactions,[15] and free-radicals-related reactions.[16]

$\mathrm{Li}$ and Brill[17] studied the hydrothermolysis of MP and investigated the relative rates for its three stages: decarboxylation, decarbonylation, and hydrolysis. They discovered that the hydrolysis step is rate-determining over most of the temperature range studied $\left(160-210{ }^{\circ} \mathrm{C}\right)$.

The investigation of the molecular structure of MP through microwave spectroscopy was carried out by Williams and Owen.[18] The authors showed that the most stable molecular conformation of the compound has a planar heavy-atom skeleton and the ester group adopting the cis orientation $\left(\mathrm{O}=\mathrm{C}-\mathrm{O}-\mathrm{CH}_{3}\right.$ dihedral angle equal to $\left.0^{\circ}\right)$. The barrier for the internal rotation about the $\mathrm{O}-\mathrm{C}\left(\mathrm{H}_{3}\right)$ bond was also determined $\left(5.3 \mathrm{~kJ} \mathrm{~mol}^{-1}\right)$. In part 2 of their work, Williams and Owen reported the infrared (IR) spectra of MP and other substituted methyl formates in the vapor and liquid phases and proposed assignments for the observed spectra.[19] They concluded that for each of the molecules studied the observed IR spectrum is consistent with a cis-ester molecular structure with a planar skeleton.

Two years later, a study on matrix isolation and photochemistry of MP was published by Lin et al.[20] In that study, the infrared spectra of MP isolated in argon (Ar) and nitrogen $\left(\mathrm{N}_{2}\right)$ matrices were reported for the first time. The spectroscopic information indicated that the compound should exist exclusively in the cis conformation both in the gas phase and in the asdeposited matrices. Photoirradiation of MP in isolated in Ar and $\mathrm{N}_{2}$ matrices with broadband UV light provided by a nickel sulfate filtered mercury lamp ( $\lambda \geq 235 \mathrm{~nm})$ resulted in changes in the 
spectra, which were attributed to the formation of the higher-energy trans MP conformer $\left(\mathrm{O}=\mathrm{C}-\mathrm{O}-\mathrm{CH}_{3}\right.$ dihedral angle equal to $\left.180^{\circ}\right)$, which was observed for the first time in that study.

In another work, the infrared and Raman spectra of MP were recorded in the condensed phases.[21] A comparison of the IR spectra of liquid and solid phases of the compound showed no band disappearance upon crystallization, pointing to the existence of the same conformer in both liquid and solid phases. It was also observed that a reversible solid-solid phase transition takes place at about $215 \mathrm{~K}$ and that the conformer present in both phases should be the same.

In the present study, the IR spectra of monomeric MP isolated in argon and nitrogen matrices were reinvestigated. The spectra were now assigned in detail, including those of the higher-energy trans conformer, which could be successfully generated photochemically in situ. The result of broadband UV-irradiation of the compound isolated in $\mathrm{Ar}$ and $\mathrm{N}_{2}$ matrices was also investigated. A theoretical description of the potential energy surface of MP as well as of the structure of the two conformers of the molecule was carried out using different basis sets at both the DFT(B3LYP) and MP2 levels of theory.

\section{COMPUTATIONAL DETAILS AND RESULTS}

\section{Computational details}

The quantum chemical calculations were performed using the Gaussian 09 program package (Rev. A.02 and Rev. D.01)[22,23] at the DFT(B3LYP)[24-26] and MP2[27] levels of theory, using the 6-311++G(d,p), 6-311++G(3df,3pd), aug-cc-pVDZ and aug-cc-pVTZ basis sets.[28-35] Relaxed one-dimensional (1-D) potential energy scans were undertaken in order to locate the minima and the transition state structures. The nature of all described stationary points on the studied potential energy surface (PES) was characterized through the analysis of the corresponding Hessian matrices. The geometries were optimized using the TIGHT convergence criteria, and the vibrational frequencies and infrared intensities were also calculated at the DFT(B3LYP)[24-26] and MP2[27] levels of theory. Transition state structures for conformational interconversion were located using the synchronous transit-guided quasi-Newton (STQN) method.[36]

Calculated vibrational frequencies and IR intensities were used to assist the analysis of the experimental spectra. The calculated harmonic wavenumbers and infrared intensities obtained at the different levels of computation are provided in the Supplementary Information (Tables S1-S4). Along the manuscript, one will use as reference theoretical data the calculated spectra obtained at 
the DFT(B3LYP)/6-311++G(d,p) level of theory, since this model is well-known to provide reliable data for analysis of infrared spectra of this type of molecules [5-7]. Ultraviolet absorption spectra were computed at the same level, using the same functional and basis set $[37,38]$. The wavenumbers obtained by this method were scaled down by our standard scale factor for this combination of method/functional/basis set(0.978) [5-7], in order to correct them mainly for the effects of basis set limitations, neglected part of electron correlation and anharmonicity effects. The resulting (scaled) wavenumbers, together with the calculated intensities, were used to simulate the spectra shown in the figures. In these simulations, the absorptions were convoluted with a Lorenztian function having a full-width-at-half-maximum (fwhm) equal to $2 \mathrm{~cm}^{-1}$. Normal coordinate analysis was undertaken in the internal coordinates space, as described by Schachtschneider and Mortimer,[39] using the optimized geometries and harmonic force constants resulting from the DFT(B3LYP)/6-311++G(d,p) calculations. The internal coordinates used in this analysis were defined following the recommendations of Pulay et al.[40]

\section{Computational results}

\section{Geometries and Energies of MP}

In the molecule of methyl propiolate there is only one conformationally relevant degree of freedom: (i) internal rotation of the methoxy group around the $\mathrm{C} 1-\mathrm{O} 6$ bond. The calculations carried out herein at different levels of theory indicate the existence of two low energy conformers of the compound, both belonging to the $\mathrm{C}_{s}$ symmetry point group (Figure 1). They correspond to the cis and trans orientations around the $\mathrm{O}=\mathrm{C}-\mathrm{O}-\mathrm{CH}_{3}$ dihedral angle and to the conformers previously found experimentally.[18,20] In consonance with previous studies on this compound, $[18,20]$ the present calculations confirm that the most stable conformer $\left(\mathbf{I}^{\prime}\right)$ bears the $\mathrm{O}=\mathrm{C}-\mathrm{O}-\mathrm{CH}_{3}$ group in the cis orientation $\left(\mathrm{O}=\mathrm{C}-\mathrm{O}-\mathrm{CH}_{3}\right.$ dihedral angle equal to $\left.0^{\circ}\right)$, while in the higher-energy conformer $\mathrm{II}^{\prime}$ the $\mathrm{O}=\mathrm{C}-\mathrm{O}-\mathrm{CH}_{3}$ group is in the trans orientation $\left(\mathrm{O}=\mathrm{C}-\mathrm{O}-\mathrm{CH}_{3}\right.$ dihedral angle equal to $180^{\circ}$ ). Two weak hydrogen-bond-like interactions between the carbonyl oxygen atom and the two methyl out-of-the-molecular-plane hydrogen atoms, forming stabilizing intramolecular pseudo-five-membered rings $(=\mathrm{O} \cdots \mathrm{H}-\mathrm{C}$ bond length: $\sim 2.674 \AA$ ), are the main factor responsible for the stabilization of conformer $\mathbf{I}^{\prime}$ with respect to conformer $\mathbf{I I}^{\prime}$.

The relative energies of the two MP conformers calculated by DFT(B3LYP) and MP2 methods are presented in Table 1, and the obtained internal coordinates for both forms are given 
in Tables S5 and S6 (Supplementary Material). In general, the bond lengths are slightly shorter when calculated at the DFT(B3LYP) level than at the MP2 level. The same trend is followed by the bond angles, except for the $\mathrm{C}-\mathrm{O}-\mathrm{C}$ angle, for which the DFT values are larger than those obtained at the MP2 level. Comparison between the geometries of the two conformers shows that the $\mathrm{C}-\mathrm{O}-\mathrm{C}$ angle is much smaller in conformer $\mathbf{I}^{\prime}$ than that in conformer $\mathbf{I I}^{\prime}$ (e.g., 115.7 vs. $120.7^{\circ}$ at the DFT(B3LYP)/6-311++G(d,p) level). The experimental values, obtained by microwave spectroscopy[18] for conformer I' (H-C: $1.06 \AA, C \equiv C: 1.21 \AA$, C-C: $1.46 \AA, C=\mathrm{O}: 1.20 \AA, \mathrm{C}-\mathrm{O}$ :

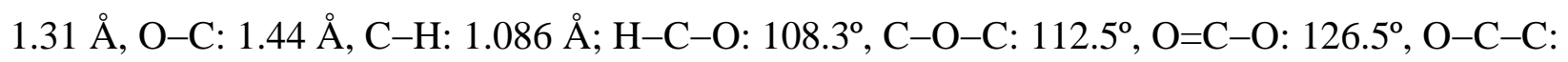
$109^{\circ}$ ), are in very good general agreement with the theoretical values obtained at both the DFT(B3LYP) and MP2 levels of calculations (see Tables S5 and S6). According to the DFT(B3LYP) calculations, the energy (including the zero-point correction) of form $\mathbf{I I}^{\prime}$ is $\sim 20.0 \mathrm{~kJ}$ $\mathrm{mol}^{-1}$ higher than that of $\mathbf{I}^{\prime}$. At the MP2 level, similar energy differences were calculated between the two conformers (see Table 1).

Figures S1 and S2 show the potential energy profiles, calculated at the DFT(B3LYP) and MP2 levels of theory, associated with the internal rotation around the $\mathrm{C}-\mathrm{O}$ bond in MP corresponding to the coordinate describing the interconversion between the two conformers. The calculated energy barriers for the $\mathbf{I}^{\prime} \rightarrow \mathbf{I I}^{\prime}$ conversion are $\sim 47$ and $\sim 49 \mathrm{~kJ} \mathrm{~mol}^{-1}$ for DFT and MP2 calculations, respectively ( $\sim 26$ and $27-30 \mathrm{~kJ} \mathrm{~mol}^{-1}$, in the reverse direction; see Figures S1 and S2). The calculated conformational energy data for MP allows concluding that only the most stable cis conformer shall be present in the deposited cryogenic matrices of the compound.

\section{EXPERIMENTAL DETAILS AND RESULTS}

\section{Experimental details}

Methyl propiolate was purchased from Sigma-Aldrich. Prior to usage, the liquid compound was placed in a glass tube which was connected to the vacuum chamber of the used helium-cooled cryostat through a needle valve. Matrices (with $\mathrm{Ar}$ (N60) and $\mathrm{N}_{2}$ (N60) used as host materials) were prepared onto a CsI substrate kept at $15 \mathrm{~K}$ using an APD Cryogenics closed-cycle helium refrigeration system with a DE-202A expander. Though the matrix:solute ratios (M:S) cannot be determined precisely in our co-deposition set up, analysis of the spectra (in particular in the $\mathrm{OH}$ stretching region) demonstrated that the used M:S was high enough to guarantee good isolation of the monomers of the compound in all investigated matrices. The temperature of the CsI window 
was measured directly at the sample holder by a silicon diode sensor connected to a digital temperature controller (Scientific Instruments, model 9650-1), which provided an accuracy of 0.1

$\mathrm{K}$. The valve nozzle was kept at room temperature (298 K), and the glass tube containing the MP to be deposited was kept at $157 \mathrm{~K}$ (immersed in an ethanol/liquid nitrogen bath).

The IR spectra, in the $4000-400 \mathrm{~cm}^{-1}$ range, were obtained using a Mattson (Infinity 60AR Series) or a Thermo Nicolet 6700 Fourier transform infrared spectrometer, equipped with a deuterated triglycine sulphate (DTGS) detector and a Ge/KBr beam splitter, with $0.5 \mathrm{~cm}^{-1}$ spectral resolution. To avoid interference from atmospheric $\mathrm{H}_{2} \mathrm{O}$ and $\mathrm{CO}_{2}$, a stream of dry air was continuously purging the optical path of the spectrometer.

Broadband irradiation of the matrices was carried out with UV light provided by a $500 \mathrm{~W}$ $\mathrm{Hg}(\mathrm{Xe})$ lamp (Newport, Oriel Instruments), with output power set to $200 \mathrm{~W}$, through the outer quartz window of the cryostat. Irradiation was performed without using any filter, i.e., at $\lambda>\sim 200$ $\mathrm{nm}$, the value defined by the onset of $\mathrm{KBr}$ transmission. Photochemical changes were detected when the IR bands belonging to the initially deposited MP decreased in intensity and new bands appeared in the IR spectra.

\section{Experimental results}

Infrared spectra of matrix-isolated methyl propiolate (as-deposited matrices)

The infrared spectra of MP monomers isolated in freshly deposited Ar and $\mathrm{N}_{2}$ matrices are presented in Figure 2 (traces a and b, respectively). Overall, the two experimental spectra are quite similar. The simulated spectrum of the most stable conformer calculated at DFT level is also shown in Figure 2c, for comparison. The good agreement between the experimental and the calculated spectra allowed an easy assignment of the fundamental bands provided in Table 2.

The definition of the internal symmetry coordinates adopted for the vibrational analysis of the two conformers of MP is displayed in Table S7 (Supplementary Material). The calculated wavenumbers, IR intensities and potential energy distributions resulting from the normal mode analyses carried out for these conformers are presented in Tables S8 and S9 (Supplementary Material).

The most significant MP bands are observed in the $v(\mathrm{CH}), v(\mathrm{C} \equiv \mathrm{C}), v(\mathrm{C}=\mathrm{O})$, and $v(\mathrm{CO})$ spectral regions. The group of bands at 3333.0, 3331.0, 3313.0, and $3309.0 \mathrm{~cm}^{-1}$ and at 3321.0 , $3320.0,3318.0$, and $3308.5 \mathrm{~cm}^{-1}$ in IR spectra originate from the $v(\mathrm{CH})$ vibration of MP isolated 
in the $\mathrm{Ar}$ and $\mathrm{N}_{2}$ matrices, respectively. The $v(\mathrm{C} \equiv \mathrm{C})$ vibration also gives rise to a site-split band with maxima at 2144.0, 2143.0, and $2135.5 \mathrm{~cm}^{-1}$ and 2410.5, 2140.0, 2136.0, 2130.0, and 2128.0 $\mathrm{cm}^{-1}$ in IR spectra of MP isolated in Ar and $\mathrm{N}_{2}$ matrices, respectively. The $v(C=O)$ stretching mode is observed in IR spectra of MP as a multiplet-type spectroscopic feature with maxima at 1738.5, $1736.5,1734.0$, and $1721.5 \mathrm{~cm}^{-1}$ in Ar matrix and at $1738.5,1737.0,1729.5$, and $1724.5 \mathrm{~cm}^{-1}$ in $\mathrm{N}_{2}$. The bands observed in IR spectra at 1240.0, 1237.5, and 1216.5 for Ar matrix and at 1251.5, $1247.0,1246.0$, and $1223.5 \mathrm{~cm}^{-1}$ for $\mathrm{N}_{2}$ matrix are ascribable to $v(\mathrm{CO})$, which corresponds to the MP vibrational mode predicted to have the strongest IR band (see Table 2). These four modes were reported by Williams and Owen[19] to give rise to bands at 3329/3300, 2130, 1747, and $1242 \mathrm{~cm}^{-}$ ${ }^{1}$ in the gas phase. On the other hand, bands at 749.5/747.0 (Ar) and $750.5 \mathrm{~cm}^{-1}\left(\mathrm{~N}_{2}\right)$ and 593.5 (Ar) and $591.5 \mathrm{~cm}^{-1}\left(\mathrm{~N}_{2}\right)$, which are assigned to the $\gamma(\mathrm{C} \equiv \mathrm{C})$ and $\delta(\mathrm{CC}=\mathrm{O})$ vibrational modes, respectively, have not been previously observed in the IR spectrum of the compound in the gas phase.[19] All IR bands assigned in the present study in the spectra of the compound have counterparts for both argon and nitrogen matrices, except for the band at $670.0 \mathrm{~cm}^{-1}\left(\mathrm{~N}_{2}\right)$, attributed to the $\delta(\mathrm{C} \equiv \mathrm{C})$ mode, which is not observed for argon matrix. Besides bands assigned to the fundamental vibrations of conformer $\mathbf{I}^{\prime}$ of $\mathrm{MP}$, additional bands were detected in the spectra of the matrix-isolated compound (as well as for the vapor phase) that shall be ascribed to overtones and combination tones. These bands have also been included in Table 2 and appear at 2916.5, 2848.0, 2462.0, 2085.5, 1768.5, 1761.0, 1747.0, 1694.5/1691.0, 1370.0/1368.0, 1361.5, 1354.0/1349.0, 1333.5, 1295.5, and 1034.0/1025.5 $\mathrm{cm}^{-1}$ for Ar, with counterparts for $\mathrm{N}_{2}$ at 2905.5, 2844.0, 2100.0, 1777.0, 1761.0, 1696.0/1686.0, 1373.5/1372.0, 1366.0/1364.0, 1357.5/1356.0, 1064.5/1063.0, and $1034.5 / 1028.0 \mathrm{~cm}^{-1}$ and at 2910, 2850, 2090, 1700, 1370, 1330, 1282, 1067, and $1025 \mathrm{~cm}^{-1}$ in the gas phase.[19]

\section{Broadband UV Irradiation $(\lambda>200 \mathrm{~nm})$}

Upon broadband UV irradiation $(\lambda>\sim 200 \mathrm{~nm})$ of matrix-isolated monomeric MP, the bands initially present in the spectra decreased in intensity while new bands were formed. Irradiation was performed close to the absorption maximum, of the UV spectrum of the compound in both cyclohexane and water solutions (Figure S3). According to the performed TD-DFT(B3LYP)/6$311++\mathrm{G}(\mathrm{d}, \mathrm{p})$ calculations on the reactant conformer of MP (see Table S10 in the Supplementary Information), the bright-state is $\mathrm{S}_{3}\left(\mathrm{~A}^{-}\right.$symmetry) predicted at $207 \mathrm{~nm}\left(578 \mathrm{~kJ} \mathrm{~mol}^{-1}\right)$ with an 
oscillator strength of 0.0801 . The calculations predict that $S_{1}$ stays $257 \mathrm{~nm}$ higher in energy than the ground state $\left(464 \mathrm{~kJ} \mathrm{~mol}^{-1}\right)$.

A detailed analysis of the infrared spectra after irradiation of the matrices revealed that the appearance of these new bands is the result of photo-induced $\mathrm{I}^{\prime} \rightarrow \mathrm{II}^{\prime}$ conformational isomerization (see Figure 3). The appearance of new bands was discernible after a few minutes of irradiation of the compound isolated in argon matrix (the total irradiation time in this matrix was 150 min and led to about $73.3 \%$ conversion of form $\mathrm{I}^{\prime}$ into $\mathrm{II}^{\prime}$ ). For the $\mathrm{N}_{2}$ matrix, the irradiation yields essentially the same results, however, aggregation of the compound along irradiation was much more significant in this matrix, allowing irradiation to be done only for $6 \mathrm{~min}$.

For Ar, the bands resulting from UV irradiation of the matrices were observed at 3316.0, 2149.5/2139.0/2130.5/2123.0, 1748.5/1743.5, 1457.0, 1458.5, 1449.5, 1220.5, 1147.0, 1058.5, and $741.5 \mathrm{~cm}^{-1}$, which correspond to the $v(\mathrm{CH}), v(\mathrm{C} \equiv \mathrm{C})$, and $v(\mathrm{C}=\mathrm{O})$ stretching modes, the $\delta_{\mathrm{as}}\left(\mathrm{CH}_{3}\right)^{\prime}, \delta_{\mathrm{as}}\left(\mathrm{CH}_{3}\right)^{\prime \prime}, \operatorname{rock}\left(\mathrm{CH}_{3}\right)^{\prime}, v\left(\mathrm{O}-\mathrm{CH}_{3}\right)$, and $\gamma(\mathrm{C}=\mathrm{O})$ modes (see Table 3) of the higherenergy conformer II', in agreement with its calculated IR spectra. In the work published by Lin $e t$ al.[20], new bands resulting from UV-irradiation of MP isolated in an argon matrix could only be detected at 3316, 2140, 1749, 1453, 1220, 1148, 1059 and, $742 \mathrm{~cm}^{-1}$, which are among those reported in the present work (see Table 3 for details). Those authors detected an additional band at $1757 \mathrm{~cm}^{-1}$ which is most probably due to aggregates of the compound $\left(1756.5 \mathrm{~cm}^{-1}\right.$ for Ar in our work).

No bands due to other photoproducts (namely decarbonylation or decarboxylation products) were observed neither for argon nor for nitrogen matrices, revealing that the observed photo-induced conformational isomerization takes place in a highly selective way under the experimental conditions used in this work.

Compared to the internal rotational energy barrier $\left(\sim 50 \mathrm{~kJ} \mathrm{~mol}^{-1}\right)$ the amount of energy introduced in the molecule by the performed irradiation is very large, and also the energy of the molecule in the lowest $S_{1}$ state is very high compared to the conformational isomerization barrier. Under these conditions, it is difficult to determine if the isomerization takes place in an excited state or in the ground state after decay to this latter state. Also, the reason why the UV irradiation did not lead to photolysis of the compound is also a results whose detailed explanation would require further investigations regarding the potential energy surfaces of the excited states of the molecule (in particular $S_{3}$ and $S_{1}$, but also low-lying triplet states staying located between $S_{3}$ and 
$\mathrm{S}_{0}$ ). These investigations go beyond the scope of our study, but we hope our results can stimulate theoretical chemists to look into this question in a deeper way.

\section{CONCLUSIONS}

In the present work, methyl propiolate isolated in in argon and nitrogen matrices was investigated by IR spectroscopy and by quantum chemical calculations carried out at the DFT and MP2 levels of theory. These calculations predict the existence of two low energy conformers of the compound with a planar skeleton, both belonging to the $\mathrm{C}_{s}$ symmetry point group (Figure 1). These conformers differ in the arrangement of the $\mathrm{O}=\mathrm{C}-\mathrm{O}-\mathrm{CH}_{3}$ fragment, which is cis in the most stable conformer $\mathbf{I}^{\prime}$ and trans in the higher-energy conformer $\mathbf{I I}^{\prime}$. These findings confirmed the results obtained in the previous investigations.[18,20]

Broadband in situ UV irradiation $(\lambda>\sim 200 \mathrm{~nm})$ of sole matrix-isolated conformer $\mathbf{I}^{\prime}$ of MP yielded as product conformer II', with no other photoproducts being detected. Assignments of IR spectra of both conformers have been presented, which considerably expands the vibrational information available on this molecule hitherto.

\section{Acknowledgements}

The authors acknowledge the financial support from the Portuguese "Fundação para a Ciência e a Tecnologia" (FCT) (Project PTDC/QEQ-QFI/3284/2014 - POCI-01-0145-FEDER-016617). T. N. is grateful to FCT for financial support through project PTDC/QEQ-QFI/3284/2014. The Coimbra Chemistry Centre (CQC) is also supported by FCT (Project UI0313/QUI/2013) and COMPETE-UE.

Notes

The authors declare no competing financial interest.

\section{Appendix A. Supplementary Material}

Supplementary data associated with this article can be found, in online version, ...

\section{References:}


[1] M.D.G. Faria, J.J.C. Teixeira-Dias, R. Fausto, Conformational stability for methyl acrylate: a vibrational spectroscopic and ab initio MO study, Vib. Spectrosc. 2 (1991) 43-60. https://doi.org/10.1016/0924-2031(91)85043-M.

[2] M.D.G. Faria, J.J.C. Teixeira-Dias, R. Fausto, Hydrogen bonding involving a,b-unsaturated carboxylic esters and substituted phenols: an infrared spectroscopic study, J. Mol. Struct. 263 (1991) 87-94.

[3] P.J. Tonge, R. Fausto, P.R. Carey, FTIR studies of hydrogen bonding between $\alpha, \beta$ unsaturated esters and alcohols, J. Mol. Struct. 379 (1996) 135-142. https://doi.org/10.1016/0022-2860(95)09117-3.

[4] J.M.F. Neta, R. Fausto, Molecular structure and vibrational spectra of methyl cyanoacetate: An FT-IR, raman and ab initio molecular orbital study, J. Mol. Struct. 443 (1998) 41-56. https://doi.org/10.1016/S0022-2860(97)00361-X.

[5] S. Jarmelo, R. Fausto, Molecular structure and vibrational spectra of methyl glycolate and methyl alpha-hydroxy isobutyrate, J. Mol. Struct. 509 (1999) 183-199.

[6] A. Gómez-Zavaglia, R. Fausto, Low temperature FT-IR and molecular orbital study of N,Ndimethylglycine methyl ester: Proof for different ground conformational states in gas phase and in condensed media, Phys. Chem. Chem. Phys. 5 (2003) 52-63. https://doi.org/10.1039/b209311c.

[7] A. Borba, A. Gómez-Zavaglia, L. Lapinski, R. Fausto, Matrix isolation FTIR spectroscopic and theoretical study of methyl lactate, Vib. Spectrosc. 36 (2004) 79-88. https://doi.org/10.1016/j.vibspec.2004.03.004.

[8] J. Sun, Y. Sun, E.-Y. Xia, C.-G. Yan, Synthesis of Functionalized 2-Aminohydropyridines and 2-Pyridinones via Domino Reactions of Arylamines, Methyl Propiolate, Aromatic Aldehydes, and Substituted Acetonitriles, ACS Comb. Sci. 13 (2011) 436-441. https://doi.org/10.1021/co200071v.

[9] L.L. Zhang, J. Sun, C.G. Yan, Domino reaction of arylamine, methyl propiolate, aromatic aldehyde, and indole for facile synthesis of functionalized indol-3-yl acrylates, Tetrahedron Lett. 53 (2012) 6965-6967. https://doi.org/10.1016/j.tetlet.2012.10.043.

[10] H. Gao, J. Sun, C.-G. Yan, Molecular diversity of acid-catalyzed one-pot reaction of arylamines, methyl propiolate, and isatins, Mol. Divers. 18 (2014) 511-519. https://doi.org/10.1007/s11030-014-9512-z. 
[11] G. Molteni, A. Ponti, Arylazide Cycloaddition to Methyl Propiolate: DFT-Based Quantitative Prediction of Regioselectivity, Chem. - A Eur. J. 9 (2003) 2770-2774. https://doi.org/10.1002/chem.200204681.

[12] A. Ponti, G. Molteni, DFT-based quantitative prediction of regioselectivity: Cycloaddition of nitrilimines to methyl propiolate, J. Org. Chem. 66 (2001) 5252-5255. https://doi.org/10.1021/jo0156159.

[13] T.A. Bakka, M.B. Strøm, J.H. Andersen, O.R. Gautun, Methyl propiolate and 3-butynone: Starting points for synthesis of amphiphilic 1,2,3-triazole peptidomimetics for antimicrobial evaluation, Bioorganic Med. Chem. $25 \quad$ (2017) 5380-5395. https://doi.org/10.1016/j.bmc.2017.07.060.

[14] M. Joost, L. Estevez, S. Mallet-ladeira, K. Miqueu, A. Amgoune, D. Bourissou, Mechanisms of syn-Insertion of Alkynes and Allenes into Gold- Silicon Bonds: A Comprehensive Experimental/Theoretical Study, J. Am. Chem. Soc. 136 (2014) 10373. https://doi.org/10.1021/ja504024h.

[15] A.M. Castaiio, L. Javier, Bis-insertion reactions of $\mathrm{Ru}(\mathrm{CO}$ ) $\mathrm{HCl}$ ( $\mathrm{PPh} 3$ ) 3 with methyl propiolate. The unexpected formation of (methoxycarbonylethenyl) triphenylphosphonium chloride, J. Organomet. Chem. 379 (1989) 171-175.

[16] T.G. Back, M.V. Krishna, Free-radical additions of diselenides to dimethyl acetylenedicarboxylate, methyl propiolate, and dimethyl maleate, J. Org. Chem. 53 (1988) 2533-2536. http://www.scopus.com/inward/record.url?eid=2-s2.033845278103\&partnerID=tZOtx3y1.

[17] J. Li, T.B. Brill, Spectroscopy of hydrothermal reactions 16: Kinetics of decarboxylation/hydrolysis of methyl propiolate ester and decarboxylation of propiolic acid at $150-210^{\circ} \mathrm{C}$ and 275 bar, J. Phys. Chem. A. 105 (2001) 6171-6175. https://doi.org/10.1021/jp010694d.

[18] G. Williams, N.L. Owen, J. Sheridan, Spectroscopic studies of some substituted methyl formates. Part 1.-Microwave spectra and internal rotation barriers of methylfluoroformate, -propiolate, -cyanoformate, -acrylate and -acetate, Trans. Faraday Soc. 67 (1971) 922-949. https://doi.org/10.1039/TF9716700922.

[19] G. Williams, N.L. Owen, Spectroscopic studies of some substituted methyl formates. Part 2.- Infra-red spectra of methyl-fluoroformate, -cyanoformate and -propiolate, Trans. 
Faraday Soc. 67 (1971) 950-960. https://doi.org/10.1039/TF9716700950.

[20] C.Y. Lin, A. Krantz, T.D. Goldfarb, New Conformational Species. Matrix Photochemistry of Methyl Propiolate, J. Am. Chem. Soc. 94 (1972) 9282-9284. https://doi.org/10.1021/ja00781a079.

[21] J.E. Katon, T.B. BenKinney, The vibrational spectra and conformations of methyl propynoate and dimethyl 1,4-butynedioate, Spectrochim. Acta Part A Mol. Spectrosc. 39 (1983) 877-885. https://doi.org/10.1016/0584-8539(83)80168-8.

[22] M.J. Frisch, G.W. Trucks, H.B. Schlegel, G.E. Scuseria, M.A. Robb, J.R. Cheeseman, G. Scalmani, V. Barone, B. Mennucci, G.A. Petersson, et al., Gaussian 09, Revision A.02, (2009).

[23] M.J. Frisch, G.W. Trucks, H.B. Schlegel, G.E. Scuseria, M.A. Robb, J.R. Cheeseman, G. Scalmani, V. Barone, B. Mennucci, G.A. Petersson, et al., Gaussian 09, Revision D.01, (2009).

[24] S.H. Vosko, L. Wilk, M. Nusair, Accurate spin-dependent electron liquid correlation energies for local spin density calculations: a critical analysis, Can. J. Phys. 58 (1980) 12001211. https://doi.org/10.1139/p80-159.

[25] A.D. Becke, Density-functional exchange-energy approximation with correct asymptotic behavior, Phys. Rev. A. 38 (1988) 3098-3100. https://doi.org/10.1103/PhysRevA.38.3098.

[26] C. Lee, W. Yang, R.G. Parr, Development of the Colle-Salvetti correlation-energy formula into a functional of the electron density, Phys. Rev. B. 37 (1988) 785-789. https://doi.org/10.1103/PhysRevB.37.785.

[27] C. Møller, M.S. Plesset, Note on an approximation treatment for many-electron systems, Phys. Rev. 46 (1934) 618-622. https://doi.org/10.1103/PhysRev.46.618.

[28] A.D. McLean, G.S. Chandler, Contracted Gaussian basis sets for molecular calculations. I. Second row atoms, $Z=11-18$, J. Chem. Phys. 72 (1980) 5639-5648. https://doi.org/10.1063/1.438980.

[29] R. Krishnan, J.S. Binkley, R. Seeger, J.A. Pople, Self-consistent molecular orbital methods. XX. A basis set for correlated wave functions, J. Chem. Phys. 72 (1980) 650-654. https://doi.org/10.1063/1.438955.

[30] M.J. Frisch, J.A. Pople, J.S. Binkley, Self-consistent molecular orbital methods 25. Supplementary functions for Gaussian basis sets, J. Chem. Phys. 80 (1984) 3265-3269. 
https://doi.org/10.1063/1.447079.

[31] R. Hammoum, M.D. Fontana, P. Bourson, V.Y. Shur, Characterization of PPLNmicrostructures by means of Raman spectroscopy, Appl. Phys. A. 91 (2008) 65-67. https://doi.org/10.1007/s00339-007-4356-3.

[32] T.H. Dunning, Gaussian basis sets for use in correlated molecular calculations. I. The atoms boron through neon and hydrogen, J. Chem. Phys. 90 (1989) 1007-1023. https://doi.org/10.1063/1.456153.

[33] R.A. Kendall, T.H. Dunning, R.J. Harrison, Electron affinities of the first-row atoms revisited. Systematic basis sets and wave functions, J. Chem. Phys. 96 (1992) 6796-6806. https://doi.org/10.1063/1.462569.

[34] D.E. Woon, T.H. Dunning, Gaussian basis sets for use in correlated molecular calculations. III. The atoms aluminum through argon, J. Chem. Phys. 98 (1993) 1358-1371. https://doi.org/10.1063/1.464303.

[35] E.R. Davidson, Comment on "Comment on Dunning's correlation-consistent basis sets," Chem. Phys. Lett. 260 (1996) 514-518. https://doi.org/10.1016/0009-2614(96)00917-7.

[36] C. Peng, H. Bernhard Schlegel, Combining Synchronous Transit and Quasi-Newton Methods to Find Transition States, Isr. J. Chem. 33 (1993) 449-454. https://doi.org/10.1002/ijch.199300051.

[37] C. Adamo, D. Jacquemin, The calculations of excited-state properties with Time-Dependent Density Functional Theory, Chem. Soc. Rev. 42 (2013) 845-856.

[38] A. D. Laurent, C. Adamo, D. Jacquemin, Dye chemistry with time-dependent density functional theory, Phys. Chem. Chem. Phys. 16 (2014) 14334-14356.

[39] J.H. Schachtschneider, Vibrational Analysis of Polyatomic Molecules, VI: FORTRAN IV Programs for Solving the Vibrational Secular Equation and for the Least-squares Refinement of Force Constants, Shell Development Company, 1965.

[40] P. Pulay, G. Fogarasi, F. Pang, J.E. Boggs, Systematic ab initio gradient calculation of molecular geometries, force constants, and dipole moment derivatives, J. Am. Chem. Soc. 101 (1979) 2550-2560. https://doi.org/10.1021/ja00504a009. 


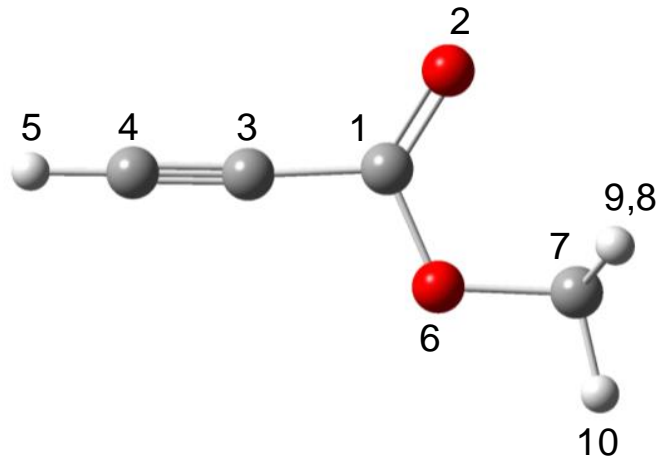

$\mathbf{I}^{\prime}$

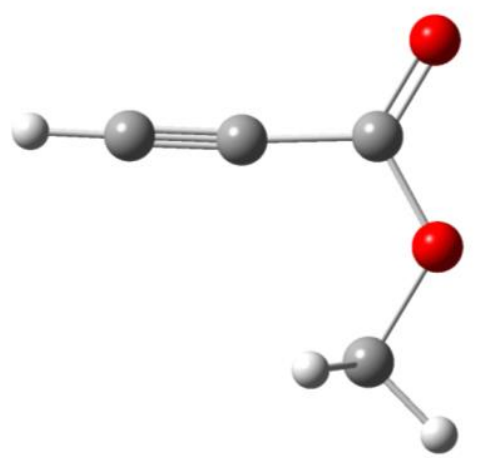

II $^{\prime}$

Figure 1. DFT(B3LYP)/6-311++G(d,p) optimized structures for conformers $\mathbf{I}^{\prime}$ and $\mathbf{I I}^{\prime}$ of methyl propiolate, including numbering of atoms adopted in this work. Colors: $\mathrm{C}$-grey, $\mathrm{H}$-white, $\mathrm{O}$-red. 


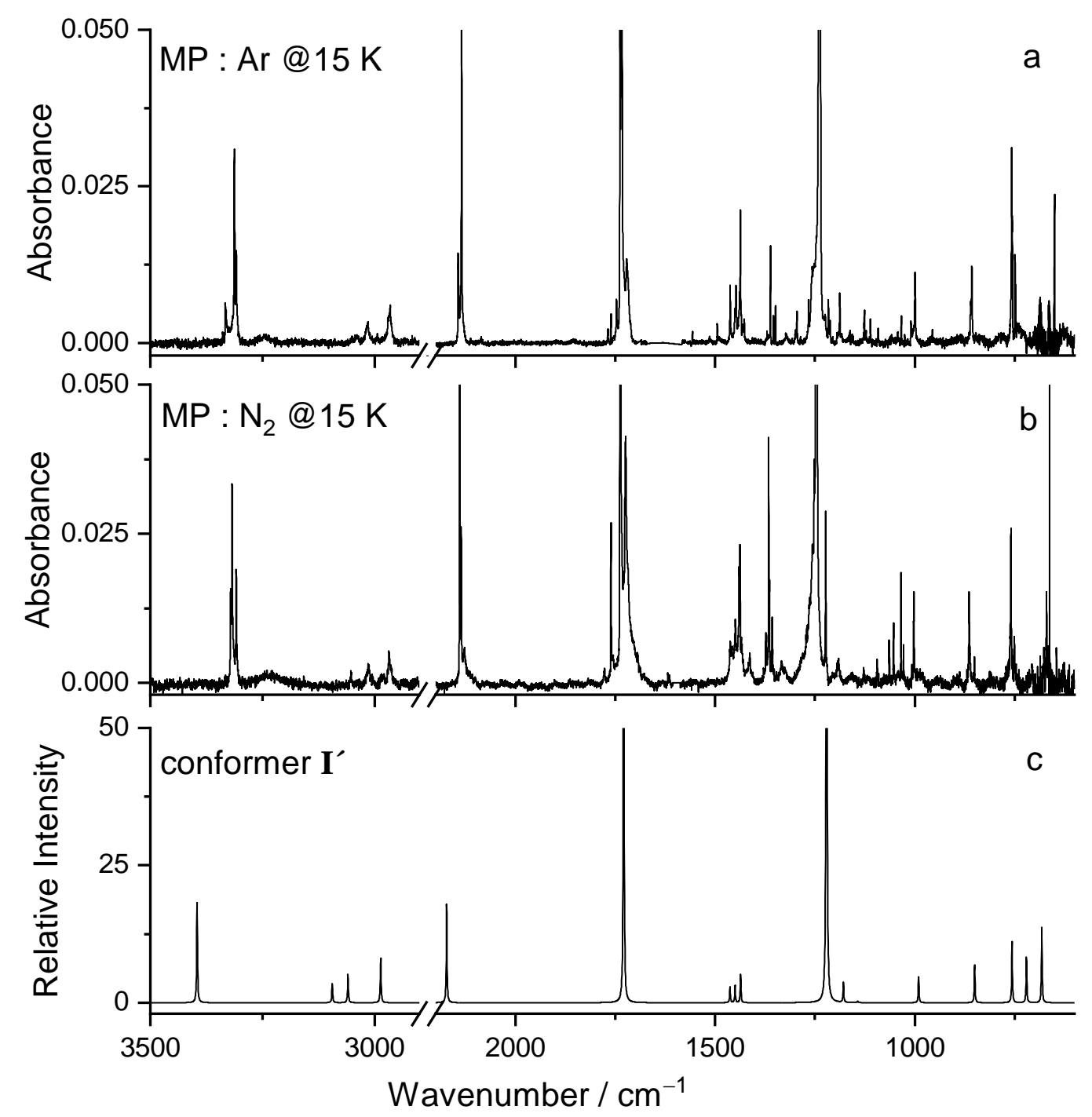

Figure 2. Experimental FTIR spectra of MP isolated in Ar and $\mathrm{N}_{2}$ matrices at $15 \mathrm{~K}$ after deposition (a and b); theoretical infrared spectrum with the harmonic frequencies (c) calculated at DFT(B3LYP)/6-311++G(d,p) level. For a graphical comparison of theoretical spectra with experiment, the calculated harmonic frequencies were scaled by a factor of 0.978 , together with the calculated infrared intensities, were used to convolute each peak with a Lorentzian function having a full width at half-maximum (fwhm) of $2 \mathrm{~cm}^{-1}$, so that the integral band intensities correspond to the calculated infrared absolute intensity. 

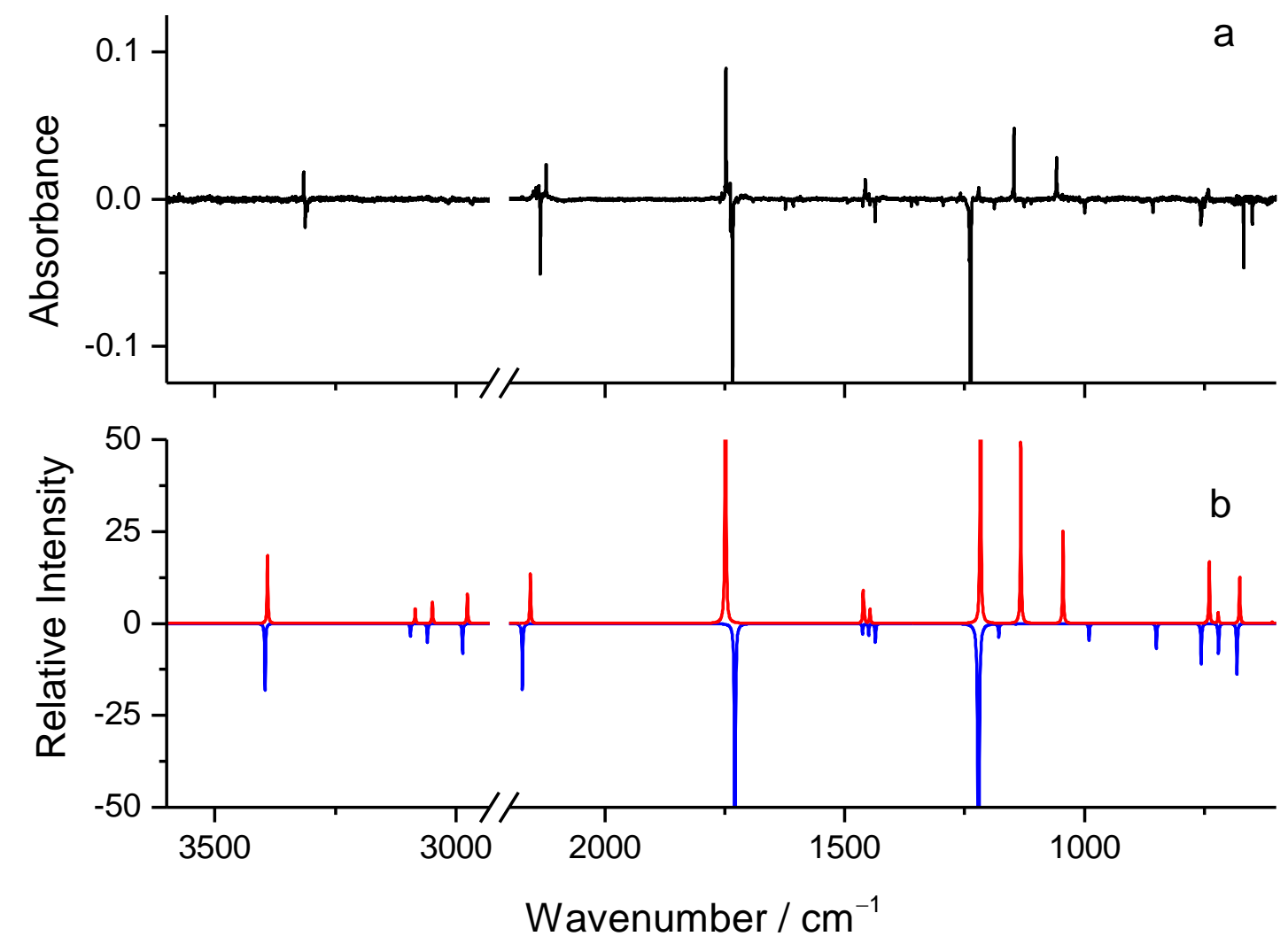

Figure 3. Experimental FTIR difference spectrum resulting from broadband UV irradiation $(\lambda>$ $235 \mathrm{~nm}$ ) of MP isolated in Ar matrix during $150 \mathrm{~min}$ (a). Growing bands pointing up show bands due to the high-energy conformer (II') of MP while negative bands are due to the most stable form (I') consumed. Simulated infrared spectrum of conformer $\mathbf{I}^{\prime}$ (in blue) and simulated infrared spectrum of conformer II' (in red) calculated at DFT(B3LYP)/6-311++G(d,p) level (b). For a graphical comparison of theoretical spectra with experiment, the calculated harmonic frequencies, together with the calculated infrared intensities, were used to convolute each peak with a Lorentzian function having a full width at half-maximum (fwhm) of $2 \mathrm{~cm}^{-1}$, so that the integral band intensities correspond to the calculated infrared absolute intensity. 
Table 1. Electronic relative energies (including zero-point corrections) calculated at the DFT(B3LYP) and MP2 levels of theory for the two conformers of MP.

\begin{tabular}{lll}
\hline Method and basis set & $\begin{array}{l}\text { Conformers } \\
\mathbf{I}^{\prime}\end{array}$ & I' $^{\mathbf{S}^{\prime}}$ \\
\hline DFT(B3LYP)/ & \\
6-311++G(d,p) & 0.0 & 21.8 \\
6-311++G(3df,3pd) & 0.0 & 19.9 \\
aug-cc-pVDZ & 0.0 & 19.8 \\
aug-cc-pVTZ & 0.0 & 20.0 \\
\hline MP2/ & & \\
6-311++G(d,p) & 0.0 & 22.0 \\
6-311++G(3df,3pd) & 0.0 & 19.1 \\
aug-cc-pVDZ & 0.0 & 18.8 \\
aug-cc-pVTZ & 0.0 & 19.2 \\
\hline
\end{tabular}


Table 2. Experimental (matrix-isolation) and DFT(B3LYP)/6-311++G(d,p) calculated infrared data of conformer $\mathbf{I}^{\prime}$ of MP isolated in Ar and $\mathrm{N}_{2}$ matrices and vibrational assignments based on the results of normal coordinate analysis. ${ }^{\mathrm{a}}$

\begin{tabular}{|c|c|c|c|c|c|}
\hline \multirow{2}{*}{$\begin{array}{l}\text { Approximate } \\
\text { Description }\end{array}$} & \multicolumn{3}{|l|}{ Experimental } & \multicolumn{2}{|c|}{ Calculated } \\
\hline & $\mathrm{Ar}$ & $\mathrm{N}_{2}$ & Gas[19] & $v$ & $\mathrm{I}^{\mathrm{IR}}$ \\
\hline$v(\mathrm{CH})$ & $3333.0,3331.0,3313.0,3309.0$ & $3321.0,3320.0,3318.0,3308.5$ & $3329 / 3300$ & 3395.9 & 58.2 \\
\hline$v_{\mathrm{a}}\left(\mathrm{CH}_{3}\right)^{\prime}$ & 3040.0 & 3053.0 & 3030 & 3094.6 & 11.2 \\
\hline$v_{\mathrm{a}}\left(\mathrm{CH}_{3}\right)^{\prime \prime}$ & 3015.5 & 3014.5 & 3006 & 3059.5 & 16.2 \\
\hline$v_{\mathrm{s}}\left(\mathrm{CH}_{3}\right)$ & $2970.5,2965.5$ & 2968.5 & 2963 & 2986.6 & 25.8 \\
\hline $\operatorname{rock}\left(\mathrm{CH}_{3}\right)^{\prime}+v(\mathrm{C}=\mathrm{O})$ & 2916.5 & 2905.5 & 2910 & 2920.3 & 0.1 \\
\hline$\delta(C \equiv C)+v(C \equiv C)$ & 2848.0 & 2844.0 & 2850 & 2832.1 & 0.2 \\
\hline$\delta(\mathrm{CC})+v(\mathrm{C}=\mathrm{O})$ & 2462.0 & n.obs. & 2470 & 2472.6 & $<0.1$ \\
\hline$v(\mathrm{C} \equiv \mathrm{C})$ & $2144.0,2143.0,2135.5$ & $2140.5,2140.0,2136.0,2130.0,2128.0$ & 2130 & 2172.4 & 57.6 \\
\hline$v\left(\mathrm{O}-\mathrm{CH}_{3}\right)+\operatorname{rock}\left(\mathrm{CH}_{3}\right)^{\prime \prime}$ & 2085.5 & 2100.0 & 2090 & 2128.6 & $<0.1$ \\
\hline$\delta(\mathrm{CC}=\mathrm{O})+\operatorname{rock}\left(\mathrm{CH}_{3}\right)^{\prime \prime}$ & 1768.5 & 1777.0 & n.obs. & 1774.5 & 0.2 \\
\hline$\gamma(\mathrm{CC})+v(\mathrm{CO})$ & 1761.0 & 1761.0 & n.obs. & 1756.9 & 3.1 \\
\hline$\delta(\mathrm{CC}=\mathrm{O})+\operatorname{rock}\left(\mathrm{CH}_{3}\right)^{\prime \prime}$ & 1747.0 & n.obs. & n.obs. & 1740.0 & $<0.1$ \\
\hline$v(\mathrm{C}=\mathrm{O})$ & $1738.5,1736.5,1734.0,1721.5$ & $1738.5,1737.0,1729.5,1724.5$ & 1747 & 1729.1 & 325.1 \\
\hline $2 \times \delta(\mathrm{OCC})$ & $1694.5,1691.0$ & $1696.0,1686.0$ & 1700 & 1703.5 & 3.9 \\
\hline$\delta_{\text {as }}\left(\mathrm{CH}_{3}\right)^{\prime}$ & 1462.5 & $1463.5,1462.5$ & 1455 & 1462.8 & 9.6 \\
\hline$\delta_{\mathrm{as}}\left(\mathrm{CH}_{3}\right)^{\prime \prime}$ & $1450.0,1448.0$ & $1451.0,1449.5$ & 1443 & 1450.1 & 10.2 \\
\hline$\delta_{\mathrm{s}}\left(\mathrm{CH}_{3}\right)$ & $1439.0,1437.0,1435.0$ & $1440.0,1437.0,1434.5$ & 1435 & 1436.1 & 16.4 \\
\hline$v(\mathrm{CC})+\delta(\mathrm{OCC})$ & $1370.0,1368.0$ & $1373.5,1372.0$ & 1370 & 1384.1 & 0.3 \\
\hline$\delta(\mathrm{C} \equiv \mathrm{C})+v(\mathrm{CO})$ & 1361.5 & $1366.0,1364.0$ & & 1368.1 & 0.7 \\
\hline$\tau(\mathrm{CO})+v(\mathrm{CO})$ & $1354.0,1349.0$ & $1357.5,1356.0$ & & 1354.7 & $<0.1$ \\
\hline$\delta(\mathrm{C} \equiv \mathrm{C})+\operatorname{rock}\left(\mathrm{CH}_{3}\right)^{\prime}$ & 1333.5 & n.obs. & 1330 & 1341.1 & 0.1 \\
\hline $2 \times \delta(C \equiv C)$ & 1295.5 & n.obs. & 1282 & 1295.7 & 7.5 \\
\hline$v(\mathrm{CO})$ & $1240.0,1237.5,1216.5$ & $1251.5,1247.5,1246.0,1223.5$ & 1242 & 1221.0 & 593.0 \\
\hline $\operatorname{rock}\left(\mathrm{CH}_{3}\right)^{\prime}$ & 1188.0 & 1191.0 & 1190 & 1178.7 & 11.9 \\
\hline $\operatorname{rock}\left(\mathrm{CH}_{3}\right)^{\prime \prime}$ & $1127.0,1126.5,1122.0$ & 1128.5 & 1118 & 1143.0 & 0.8 \\
\hline $2 \times v(\mathrm{CC})$ & n.obs. & $1064.5,1063.0$ & 1067 & 1062.5 & 0.3 \\
\hline$\delta(\mathrm{CC})+\gamma(\mathrm{C}=\mathrm{O})$ & n.obs. & 1053.0 & n.obs. & 1052.7 & 2.3 \\
\hline$\delta(\mathrm{CC})+\gamma(\mathrm{C} \equiv \mathrm{C})$ & $1034.0,1025.5$ & $1034.5,1028.0$ & 1025 & 1024.0 & 0.8 \\
\hline
\end{tabular}




\begin{tabular}{|c|c|c|c|c|c|}
\hline$v\left(\mathrm{O}-\mathrm{CH}_{3}\right)$ & $1010.0,999.5$ & $1007.5,1003.0,1002.0$ & 1005 & 990.3 & 15.1 \\
\hline$\delta(\mathrm{OCC})$ & $860.5,857.0$ & $864.0,850.5$ & 855 & 850.0 & 21.8 \\
\hline$\gamma(\mathrm{C}=\mathrm{O})$ & $757.5,756.0$ & 759.5 & 756 & 756.4 & 35.5 \\
\hline$\gamma(\mathrm{C} \equiv \mathrm{C})$ & $749.5,747.0$ & 750.5 & n.obs. & 720.4 & 26.4 \\
\hline$\delta(\mathrm{C} \equiv \mathrm{C})$ & n.obs. & 670.0 & 685 & 681.9 & 43.3 \\
\hline$\delta(\mathrm{CC}=\mathrm{O})$ & 593.5 & 591.5 & n.obs. & 586.9 & 5.5 \\
\hline$v(\mathrm{CC})$ & n.i. & n.i. & & 532.1 & 2.0 \\
\hline$\gamma(\mathrm{CC})$ & n.i. & n.i. & & 301.5 & 12.6 \\
\hline$\delta(\mathrm{CC})$ & n.i. & n.i. & & 290.4 & 0.0 \\
\hline$\delta(\mathrm{C} \equiv \mathrm{C})$ & n.i. & n.i. & & 163.3 & 7.0 \\
\hline$\tau(\mathrm{CO})$ & n.i. & n.i. & & 141.5 & 4.4 \\
\hline$\tau \mathrm{CH}_{3}$ & n.i. & n.i. & & 119.7 & 2.6 \\
\hline
\end{tabular}

${ }^{a}$ Wavenumbers $\left(\mathrm{cm}^{-1}\right.$, scaled by 0.978$)$, calculated intensities $\left(\mathrm{km} \mathrm{mol}^{-1}\right), \mathrm{s}=$ symmetric; $\mathrm{a}=$ antisymmetric; $v=$ stretching; $\delta=$ in-plane bending; $\gamma=$ out-ofplane bending; $\tau=$ torsion; rock = rocking; n.obs. = not observed; n.i. = not investigated. See Table S7 for definition of symmetry coordinates and Table S8 for potential energy distributions of conformer $\mathbf{I}^{\prime}$. 
Table 3. Experimental (matrix-isolation) and DFT(B3LYP)/6-311++G(d,p) calculated infrared data of conformer II' of MP isolated in Ar and $\mathrm{N}_{2}$ matrices and vibrational assignments based on the results of normal coordinate analysis. ${ }^{\text {a }}$

\begin{tabular}{|c|c|c|c|c|c|}
\hline \multirow{2}{*}{$\begin{array}{l}\text { Approximate } \\
\text { Description }\end{array}$} & \multicolumn{3}{|l|}{ Experimental } & \multicolumn{2}{|c|}{ alculated } \\
\hline & $\mathrm{Ar}$ & $\mathrm{N}_{2}$ & $\operatorname{Ar}[20]$ & $v$ & $\mathrm{I}^{\mathrm{IR}}$ \\
\hline$v(\mathrm{CH})$ & 3316.0 & n.obs. & 3316 & 3390.9 & 59.4 \\
\hline$v_{a}\left(\mathrm{CH}_{3}\right)^{\prime}$ & n.obs. & n.obs. & & 3084.8 & 13.4 \\
\hline$v_{a}\left(\mathrm{CH}_{3}\right)^{\prime \prime}$ & n.obs. & n.obs. & & 3049.3 & 19.4 \\
\hline$v_{\mathrm{s}}\left(\mathrm{CH}_{3}\right)$ & n.obs. & n.obs. & & 2976.5 & 25.1 \\
\hline$v(\mathrm{C} \equiv \mathrm{C})$ & $2149.5,2139.0$ & 2128.0 & 2140 & 2155.8 & 43.9 \\
\hline & 1756.5 & n.obs. & 1757 & n.i. & \\
\hline$v(\mathrm{C}=\mathrm{O})$ & $1748.5,1743.5$ & $1733.0,1718.5$ & 1749 & 1748.8 & 410.2 \\
\hline$\delta_{\mathrm{as}}\left(\mathrm{CH}_{3}\right)^{\prime}$ & 1457.0 & 1461.0 & 1453 & 1461.7 & 26.4 \\
\hline$\delta_{\mathrm{as}}\left(\mathrm{CH}_{3}\right)^{\prime \prime}$ & 1458.5 & n.obs. & & 1459.6 & 11.5 \\
\hline$\delta_{\mathrm{s}}\left(\mathrm{CH}_{3}\right)^{\prime}$ & 1449.5 & n.obs. & & 1447.2 & 13.1 \\
\hline$v(\mathrm{CO})$ & 1220.5 & 1229.5 & 1220 & 1216.9 & 341.5 \\
\hline $\operatorname{rock}\left(\mathrm{CH}_{3}\right)^{\prime \prime \prime}$ & n.obs. & n.obs. & & 1140.3 & 0.7 \\
\hline $\operatorname{rock}\left(\mathrm{CH}_{3}\right)^{\prime}$ & 1147.0 & n.obs. & 1148 & 1132.8 & 161.8 \\
\hline$v\left(\mathrm{O}-\mathrm{CH}_{3}\right)$ & 1058.5 & 1057.5 & 1059 & 1044.6 & 80.3 \\
\hline$v(\mathrm{CC})$ & n.obs. & n.obs. & & 744.2 & 0.3 \\
\hline$\gamma(\mathrm{C}=\mathrm{O})$ & 741.5 & 751.0 & 742 & 739.6 & 53.7 \\
\hline$\gamma(\mathrm{C} \equiv \mathrm{C})$ & n.i. & n.i. & & 721.0 & 9.1 \\
\hline$\delta(\mathrm{C} \equiv \mathrm{C})$ & n.i. & n.i. & & 676.2 & 41.4 \\
\hline$\delta(\mathrm{CC}=\mathrm{O})$ & n.i. & n.i. & & 608.3 & 1.2 \\
\hline$\delta(\mathrm{OCC})$ & n.i. & n.i. & & 526.2 & 13.5 \\
\hline$\delta\left(\mathrm{C}-\mathrm{O}-\mathrm{CH}_{3}\right)$ & n.i. & n.i. & & 318.1 & 2.1 \\
\hline$\gamma(\mathrm{CC})$ & n.i. & n.i. & & 244.4 & 0.3 \\
\hline$\delta(\mathrm{CC})$ & n.i. & n.i. & & 160.4 & 3.0 \\
\hline$\tau \mathrm{CH}_{3}$ & n.i. & n.i. & & 147.4 & 2.0 \\
\hline$\tau(\mathrm{CO})$ & n.i. & n.i. & & 92.8 & 0.3 \\
\hline
\end{tabular}

${ }^{a}$ Wavenumbers $\left(\mathrm{cm}^{-1}\right.$, scaled by 0.978$)$, calculated intensities $\left(\mathrm{km} \mathrm{mol}^{-1}\right), \mathrm{s}=$ symmetric; $\mathrm{a}=$ antisymmetric; $v=$ stretching; $\delta=$ in-plane bending; $\gamma=$ out-of-plane bending; $\tau=$ torsion; rock = rocking; n.obs. $=$ not observed; n.i. $=$ not investigated. See Table S7 for definition of symmetry coordinates and Table S9 for potential energy distributions of conformer II'. 